\title{
Mapping the Situation of Educational Technologies in the Spanish University System Using Social Network Analysis and Visualization
}

\author{
B. Vargas-Quesada ${ }^{1 *}$, C. Zarco ${ }^{2}$, O. Cordón ${ }^{3}$ \\ ${ }^{1}$ Information and Communication Department, University of Granada, Granada (Spain) \\ ${ }^{2}$ Department of Market Research, Universidad Internacional de La Rioja, Logroño (Spain) \\ ${ }^{3}$ Andalusian Research Institute in Data Science and Computational Intelligence (DaSCI), University of \\ Granada, Granada (Spain)
}

Received 12 February 2021 | Accepted 23 July 2021 | Early Access 29 September 2021

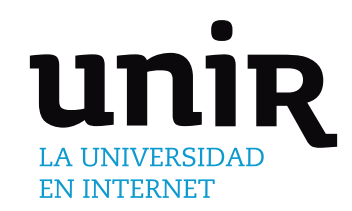

KEYWORDS

Educational

Technologies,

Information and

Communication

Technologies, Maps,

Social Network Analysis,

Spanish Higher

Education System,

Universities.

DOI: $10.9781 /$ ijimai.2021.09.004

\section{IntRODUCTION}

SINCE early 2020, the Covid-19 pandemic in Spain and its evolution have led to the adoption of extraordinary containment measures imposed by the national government, the 17 regional governments, and each university Rector's office, with regard to the suspension of face-to-face academic activity and/or its maintenance in distance mode, for all centers of primary, secondary and higher education.

The role of Information and Communication Technologies (ICT) in every social sector has clearly grown in impact on the educational system and current approaches to education, whether formal (primary education, high schools, universities) or other means of training (business and lifelong education at home). Indeed, virtual learning has become a necessity over the past year. The Covid-19 has given rise to new educational methodologies - more focused on students - to be applied in different contexts, and the generation of new content formats. When directly related to teaching innovation, such concepts translate as the use of multimedia technologies and the Internet to improve the quality of teaching and learning, facilitating access to resources and services, while promoting collaboration and knowledge

${ }^{*}$ Corresponding author.

E-mail address: benjamin@ugr.es exchange. Nowadays, this is known as Educational Technologies (EdTech) [1], [2].

Higher education cannot turn its back on such transformations. Universities are busily establishing methodologies, protocols, and training programs for their staff, and progressively fomenting technical and methodological support units, so as to implement EdTech in everyday teaching activities. Given the importance of this issue, a number of reports have been put out by European university systems, including: EDUCAUSE Horizon Reports 2019 Higher Education Edition [3], Open University Innovation Report 7 [4], and Top 10 Strategic Technologies Impacting Higher Education in 2019 [5], all of them at the worldwide level, re-imagining the role of technology in higher education. Supplements refer to the National Education Technology Plan [6] for the US university system and the 2018 Survey of Technology Enhanced Learning for Higher Education in the UK [7], for the UK university system.

Unfortunately, no study of this type was available for the Spanish University System (SUS) until now. Thus, in 2017, the ICT Sectorial of the Commission of Rectors of Spanish Universities (the Spanish University Association, CRUE Universidades Españolas) tackled the matter of evaluating the application of EdTech in Spanish universities and developing a situation report, the latter task being entrusted to the Working Group in Online Training and Educational Technologies (FOLTE). In order to accurately reflect the actual state of this endeavor, 
the members of the FOLTE group designed a large survey around 28 thematic blocks (topics) selected from a previous study based on national and international references, aiming to cover the entire spectrum of EdTech and on-line training methods and tools to date. The first situational report considered by the SUS as a result of this survey provided the response of a large sample of 47 universities [8], a high percentage $(62.5 \%)$ of the 75 universities in Spain. What is more, these 47 universities represent roughly $63 \%$ of the 1.5 million students in the SUS in 2017. Such figures underline the relevance of the data dealt with in this paper and point to the global interest in the outcomes described.

Briefly, our current research efforts are aimed to design a series of maps reflecting the situation of EdTech in the SUS based on data available from the survey conducted by the FOLTE group. To do so, we pre-processed information in order to represent it as a bipartite network that links universities to their adopted technologies; we also consider advanced data visualization tools based on social network analysis (SNA) techniques [9]. Specifically, we will design two different maps that will represent respectively the penetration of the different types of technologies in our university system and the strategic interest of the universities for their adoption. In addition, the strategic interest map will be analyzed in order to identify interesting relation patterns between the different universities by both considering a manual and an automatic community detection on the associated social network.

With the firm belief that inter-university collaboration is the solution for the universal educational community (the essential meaning of University) in the current situation of contingency, our final objective is to provide a case study through a series of maps based on social networks that facilitate detailed analysis of today's relationships among technologies/universities. The maps must be user-friendly, easily understandable for information analysts looking at the distribution and spatial location of the corresponding nodes. They may therefore stand as a technological support tool for Spanish university managers who must make strategic decisions about the adoption of EdTech in their universities. The methodology can moreover be extended to the university systems of other countries. For instance, two situation reports developed by Argentina's MetaRed University Association (http://metared.com.ar) [10], Mexico's ANUIES (http://www.anuies.mx/) and MetaRed University Associations (https://www.metared.org/mx/index.html) [11] have been recently developed following the methodology used by the FOLTE group. Situation maps derived from the data collected under the Argentinian and Mexican systems could therefore be easily obtained to analytically compare the situation of the two domains and arrive at projections for the near future.

The main contributions of the current manuscript are as follows:

1. The situation of the adoption of EdTech in the university system of an entire country, the SUS, is summarized in a single visual representation. On the one hand, it becomes a very useful analysis tool for professors, researchers, and specially university managers. On the other hand, this constitutes an interesting case study of the application of advanced data visualization tools based on SNA.

2. The proposed methodology has important advantages. It generates highly interpretable maps where the information analyst can identify inherent global relations at first glance, thus becoming a powerful knowledge discovery tool. Thus, the results of our study allow us to uncover interesting insight about the situation of EdTech in the SUS, both from the point of view of the adoption of the different EdTech and especially from the viewpoint of the strategic interests of the Spanish universities. Some of these conclusions were already drawn in the FOLTE report from which the survey data used to generate the maps was obtained, but others improve upon these or are even completely novel and highly informative.

3. As the obtained maps are based on social networks, different SNA methods can be applied on them to develop additional knowledge discovery tasks. Specifically, in the current work we apply a community detection method to supplement the expert analysis developed in the strategic interest map of the Universities.

\section{BACKGROUND}

\section{A. Educational Technologies}

EdTech is a field of knowledge born in the 1950s and meant to provide a response to the incorporation of media and materials into education [1]. The area is very widespread given the need for innovative proposals that contribute to training processes, to improving the quality of educational services, and to renewing contents so that they respond to teaching demands [12], [13]. In the last few decades, numerous developments have stemmed from the use of ICT in teaching [14], [15]. The Internet, interactive media, mobile devices, and many other technologies have expanded the potential for teaching and learning inside and outside the classroom, both for students and for teachers [2], [16]. Novel teaching methodologies include the flipped classroom [17] and SPOC courses, personalized learning based on learning analytics [18], [19], new "disaggregated" educational formats such as MOOC courses [20], [21], the use of mobile devices, physical spaces for teaching as the Makerspaces, and methods of certification as Blockchain. These are just some examples of the great variety of methods and techniques that comprise EdTech.

\section{B. The CRUE TIC FOLTE Working Group}

Well aware of the importance of this discipline for improving the quality of university teaching in Spain, the CRUE Association created the FOLTE Working Group in December 2016, in the framework of its ICT Sectorial (http://tic.crue.org). Currently, the group is made up of more than 100 members from 55 Spanish Universities, both public and private, in addition to experts having a technical and/or academic background. Although the main focus of the group is on the ICT aspects of EdTech, because it has a multidisciplinary nature, it also analyzes methodological and instructional aspects of education. The main information, objectives and lines of work of FOLTE can be found at http://tic.crue.org/grupos-de-trabajo/formacion-online-ytecnologias-educativas.

\section{Situation of Educational Technologies in Spanish Universities}

The University plays a key role in the development of ICT with academic objectives. The daily use of technology calls for an essential change in the way it is learned and taught. Although EdTech have evolved over several decades and has demonstrated its importance for university teaching, the different UNIVERSITIC reports (http:// www.crue.org/SitePages/Universitic.aspx) [22] put out by CRUE in recent years reflect a substantial shift of focus, toward consolidating ICT infrastructures and university support services. Even so, their implementation in Spanish universities is not always fully developed, depending largely on the specific institution involved. There are diverse reasons behind this fact: an attitude of rejection on the part of teachers accustomed to former educational models, without these technologies; teachers' lack of technological skills or training; the great diversity, variability, speed of change, and volatility of the technologies and tools used; limited technical and human resources in the University to support the application of EdTech; the absence of a strategic commitment on the part of the institution's governing body, etc. 


\section{Design and Composition of the Survey}

Fifty multidisciplinary experts from more than 40 Spanish universities participated in the elaboration of the survey. It is structured around 28 thematic blocks (topics) selected from 159 preliminary topics identified from national and international references. The 28 selected topics were grouped into four dimensions from which the working group wanted to obtain information on the state of EdTech in our university system: Pedagogical/Methodological, Technological, Contents, and Management. This initiative was carried out following the TPACK Model [23], which helps identify different areas where innovation can be effectively integrated by using technology in educational contexts to enhance teaching quality. Table I reports the list of EdTech topics finally selected and the dimensions of each.

TABLE I. List of Topics And Dimensions in the FOLTE Survey

\begin{tabular}{|l|l|}
\hline \multicolumn{1}{|c|}{ Methodological } & \multicolumn{1}{c|}{ Technological } \\
\hline M1. Active learning & T1. Blockchain for learning \\
M2. Adaptive learning & T2. Digital assessment/badges to \\
M3. Flipped classroom & accredit learning \\
M4. Gamification & T3. Interoperability standards \\
M5. Mobile learning & T4. Collaborative tools \\
M6. MOOCs/SPOCs & T5. Plagiarism checking tools \\
& T6. Learning analytics \\
& T7. Learning management system \\
& (LMS) \\
& T8. Makerspaces \\
& T9. Proctoring \\
\hline \multicolumn{1}{|c|}{ Contents } & \multicolumn{1}{c|}{ Management } \\
\hline C1. Augmented and virtual reality & G1. Digital competence evaluation \\
C2. Production of audiovisual & G2. Teacher training \\
contents & G3. Teaching innovation regulation \\
C3. Automatic production of & G4. Student participation in \\
enriched video & EdTech plans \\
C4. Learning object repository & G5. Communication plans \\
& G6. Intellectual property rights \\
& (IPR) \\
& G7. Teacher return \\
& G8. Teaching innovation support \\
& unit \\
& G9. Usability and accessibility \\
\hline
\end{tabular}

Once the topics were identified, the questions associated with each of them were designed, striving for a balance between the completeness and effectiveness of the instrument. Finally, 108 questions were defined with different tradeoff levels among the topics, different types of answers, and the presence of key questions leading or not to surrogate answers. The full composition of the survey can be found in [8].

\section{MethodOLOGY}

We made use of SNA and visualization techniques to design two maps: one on the penetration of EdTech in Spanish universities, the other on the level of adoption of EdTech in those universities. SNA techniques have demonstrated their capacity to analyze different domains and generate high-quality schematic visualizations, with network-based representations in many fields of knowledge: system modeling [24], software debugging [25], multi-objective optimization [26], social media analysis [27], and scientometrics [28], among others.

There are many data visualization methodologies in the specialized literature that could be considered for this task, whose main objective is to make visible to the brain that which is not so visible to the human eye. In addition to SNA and its variant of Pathfinder networks, the most commonly used have been multidimensional scaling, clustering, principal component analysis, self-organizing maps, and geographic information system mapping [29]. Of all of them, the representations obtained with Pathfinder networks in combination with force layout (spring embedded) algorithms, seem to offer the best results [30], [31].

Comparing the use of different visualization methods is out of the scope of this contribution as our main goal was to design informative maps of the situation of EdTech adoption in the SUS that can be easily analyzed for domain experts as university managers. Hence, we have taken advantage of our expertise in information visualization to design the most appropriate visualization methodology for the current task. For example, we decided not to consider alternatives as multidimensional scaling or principal component analysis since the resulting maps would be less informative as they would lose the local relations. Additional advantages of the selected methodology are provided in Section III.C.

Map generation requires the pre-processing of data from a relational perspective to ensure that the network properly reflects all relevant information. To do so, a small application was programmed in Visual Basic for Excel ${ }^{1}$; it allowed us to build an asymmetric matrix gathering the answers given by each one of the 47 universities to the 108 questions of the survey, grouping them into the 28 topics. Our case entailed two types of analysis elements - the 28 EdTech topics considered, and the 47 universities that responded to the survey, indicating whether they had sufficient strategic interest to adopt new measures or not $^{2}$. Our relational structure is thus an undirected bipartite network, since there could only be relations (links) between nodes of the two different types (topics and universities). There would be a link between a university and a specific EdTech topic if the university had actually adopted that technology, as reflected in the survey responses; but there could not be direct links between two universities or two technologies. The links are necessarily undirected, since when a university adopts a technology, that technology has of course been adopted by the university.

The first network is associated with the introduction of the technologies. It is made up of 28 nodes, one per topic, and its relations represent the similarity between each pair of technologies, depending on their adoption in the 47 universities. Reciprocally, the second network is associated with the strategic interest shown by the Spanish universities in adoption of these technologies. This network includes 47 nodes, one per university, and its relations represent the similarity between each pair of universities, again depending on the technologies adopted by each one.

After building the original network, we apply a network pruning method, an efficient variant of the Pathfinder algorithm [32], in order to reduce the relations between the levels of penetration of the technologies, on the one hand, and their adoption, on the other. The intention is to keep only the most significant ones at a global level (i.e. the most salient relations). To obtain the visual map, a social network layout algorithm based on forces [33] is used, tracing the network by locating the nodes in the plane.

\section{A. Construction of the Bipartite and Projected Social Networks}

To compute the network weights, a numerical value is associated with each answer: value 0 for the negative answers, and value 1 for a positive response. The "Under study" answers were deliberately ignored, so that the resulting maps reflect the current situation and not the future goals of a university. Then, the values of every answer associated with each topic were aggregated and stored in a numerical array of 28 dimensions, one per topic. Finally, the calculated values were normalized. In this way, the answers of each university regarding

\footnotetext{
${ }^{1}$ Available for the interested reader upon request from the authors.

2 The source data considered is publicly available at https://tic.crue.org/ publicaciones/\#folte in CSV format.
} 
the adoption of the EdTech under the 28 topics are represented by a 28 -dimensional point in the $[0,1]^{28}$ space, while reciprocally, the penetration of each technology in the 47 universities is represented by a 47 -dimensional point in $[0,1]^{47}$ space. The final result is an adjacency matrix of dimensions $28 \times 47$ that represents the bipartite network.

As a consequence, the network is weighted, i.e. the links indicate the "strength" of the adoption relationship. The weights also reflect the data of the survey questions, as explained earlier in this section, by means of the layout algorithm used, making the most related nodes attract each other and be situated closer together, while the less related ones become more separated.

We made two projections of the bipartite network to obtain the two desired maps. The first projected network is associated with the penetration of technologies and has 28 nodes, one per topic; its relations represent the similarity between each pair of technologies depending on their adoption in the 47 universities. Thus, there is only a link between two nodes (topics) if the original bipartite network included at least one university that had adopted both technologies. Otherwise, these two technologies are not at all similar to each other. In turn, the weight of the link depends on the number of universities that share the use of both technologies; the higher the number of universities, the greater the associated weight and therefore the greater the similarity between the two EdTech topics. Since there are 47 universities in the sample, the weight of the link is defined as $\{0$, $1, \ldots, 47\}$, and then all the values are normalized by dividing them by 47. In this way, the adjacency matrix associated with the network of technologies is a symmetrical, square matrix of dimensions $28 \times 28$ with values in $[0,1]$.

Reciprocally, the second projected network is associated with the strategic interest shown by the universities in the adoption of the analyzed technologies. This network includes 47 nodes, one per university, and their relationships represent the similarity between every pair of universities depending on the technologies adopted by each. In this case, the weight of the link depends on the number of EdTech topics adopted that are shared, and its maximum value before normalization is 28 . The adjacency matrix associated with the university network is a symmetrical, square matrix of dimensions $47 \times 47$ with values in $[0,1]$. Fig. 1 reports an illustrative example of the procedure followed.

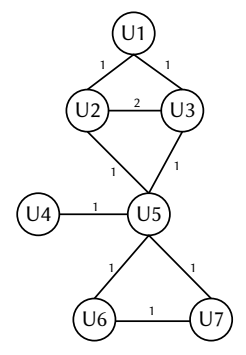

Universities projected network

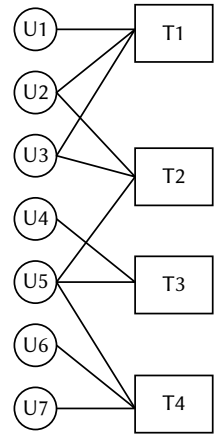

Bipartite network

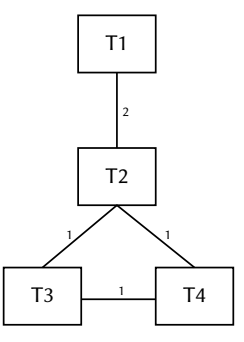

Topics projected network
Fig. 1. Illustrative example on the creation of networks of EdTech topics and universities through the projection of the bipartite network.

\section{B. Prunin the Social Networks}

Generating graphic representations that facilitate analysis and comprehension can be difficult due to the vast dimensions of social networks. This can lead to an overload of information for the specialist, impeding interpretation of the obtained maps [34]. In our domain, the two social networks of EdTech and universities have few nodes but very high density. To achieve an attractive layout, it is necessary to reduce the number of links in the network (by pruning), thus creating a map that shows only the underlying fundamental structure, leaving the $n$ original nodes and maintaining the most essential links.

The SNA literature offers three choices for pruning weighted networks [35]: a) prune the links having weights lower than a certain limit; b) obtain the minimum spanning tree network; or c) use Pathfinder pruning [36] to set limitations on the network paths and remove those links that do not fulfill them.

We chose the third alternative because of the advantages it provides for data visualization. The Pathfinder algorithm is known for having mathematical properties related to the conservation of triangular inequality in network paths of length $q$ (algorithm parameter) (see [36]) for a summary of the properties). The parametric distance (the Minkowski metric) with a parameter $r$ is used to calculate the path distances. Links not verifying the triangular inequality according to that distance metric will be removed, as they are redundant, not being included in any shortest path. When we apply the Pathfinder method with parameters $q$ and $r$ to a weighted network, a new pruned network called PFNET $(r, q)$ is obtained. Therefore, the algorithm makes it possible to perform a social network sequence with decreasing complexity when the value of $q \in\{2, \ldots, n-1\}$ increases. The PFNET $(r, q$ = 1) stands for the initial network, and the PFNET $(r, q=n$-1) includes the least possible number of links.

In our case, a quick version of the Pathfinder algorithm was used -Fast-Pathfinder [32], freely available from GitHub (https://github. com/aquirin/pathfinder). We applied values $r=\infty$ and $q=n-1$ to get maximum pruning, so as to derive more comprehensible maps.

\section{Social Networks Layout}

To draw our maps, we applied the Kamada \& Kawai algorithm [30]. This method has proven to be very effective when combined with Pathfinder networks in other situations. The Kamada-Kawai algorithm allowed us to locate the nodes of the network so that their positions in the two-dimensional space could be determined by the existing global relations, maintaining the theoretical lengths of the original network paths, and also causing few cross-links; this provided for the most aesthetic and pleasant vision possible.

The visualization resulting from the combination of Pathfinder network pruning algorithm plus Kamada-Kawai layout algorithm offers a great advantage -it resembles a subway map, which facilitates its interpretation by the information analyst in metaphoric fashion. The center and the external limits of the represented information domain can be identified simply, differentiating between the center of the map (where the nodes associated with the most important analysis elements (network nodes) are located, according to the existing relationships) and periphery (where the least relevant nodes are located) [37]. In addition, one can determine the global relationships between the different analytical elements by "moving" from one node to another along the paths formed by the links. This facilitates the identification of global similarity between the analysis elements (as a function of the number of links that make up the paths) and the spatial separation between the nodes (associated with the actual length of the links). The links with higher weights, that is, greater similarity between the analysis elements in the nodes, are shorter than those with lower weights and less similarity; pruning maintains the lowest possible number of links in the original network that preserve the geodesic distances of all the global relations, clarifying the visualization. Finally, the most important nodes can be easily identified in terms of the number of links preserved in the pruned network. Consequently, these nodes act as intermediaries with other "subway lines" (network paths), i.e. as hubs or crossing points.

To enrich the visualization of our maps, the size of the nodes is 
proportional to the weighted degree of the node (a measure that relates its number of links and the weights of these) in the original network. Hence the elements of analysis having stronger relations are seen at first glance, that is, the technologies used by more universities - and the universities that show strategic interest in the implementation of more technologies- present larger nodes in the map. The final visualization was obtained using the VOSviewer tool [38].

\section{Community Detection}

Complex networks and, consequently, social networks tend to show a community structure. Communities are simply defined as groups of similar nodes. This property usually occurs as a consequence of the global and local heterogeneity of the distribution of links in the network (the underlying graph). Based on the concept of network density, communities can be defined as groups of nodes that are densely connected internally that have scattered connections to each other. In our application domain, community detection can help us to identify interesting relation patterns between the different universities in the strategic interest social network.

There is a large number of automated community detection methods in the specialized literature [39]. In fact, this is a research area that has undergone great development in the last two decades. Louvain method [40] has been long considered as a de facto standard thanks to its good properties regarding accuracy and run time. Recently, a new method called Leiden has been proposed to fix a defect identified in the Louvain algorithm resulting in the derivation of disconnected communities. Leiden method extends Louvain by allowing it to split groups and not only join them through a fast local move approach. The new algorithm both increases the quality and speed of Louvain's [41]. Due to these reasons, the Leiden algorithm will be considered in the current contribution. Authors provide a free Java implementation (https://github.com/CWTSLeiden/networkanalysis) and a Gephi plugin (https://github.com/vtraag/gephi-leiden-plugin/), both of them available in GitHub.

\section{AnAlysis And Results}

This section is devoted to analysis of the two situation maps of EdTech in the SUS, as well as the extraction of knowledge from each one of them. This information makes it possible to study, in detail, the relations existing between the different thematic blocks of technologies from the perspective of their adoption by the different universities (penetration of EdTech in the Spanish universities) and of the relationships between the different universities with respect to the application of different technologies (strategic interest of universities in the adoption of EdTech).

\section{A. Analysis of the Educational Technologies Map}

Fig. 2 shows the visualization resulting from application of the developed methodology to the projected social network of the 28 EdTech topics considered in the FOLTE report. While the original network contained 359 links and had a density $D=0.95$, the pruned network $\operatorname{PFNET}(r, q=n-1)$ in the figure has 132 links and $D=0.35$.

The obtained map is schematic and clear, allowing us to identify

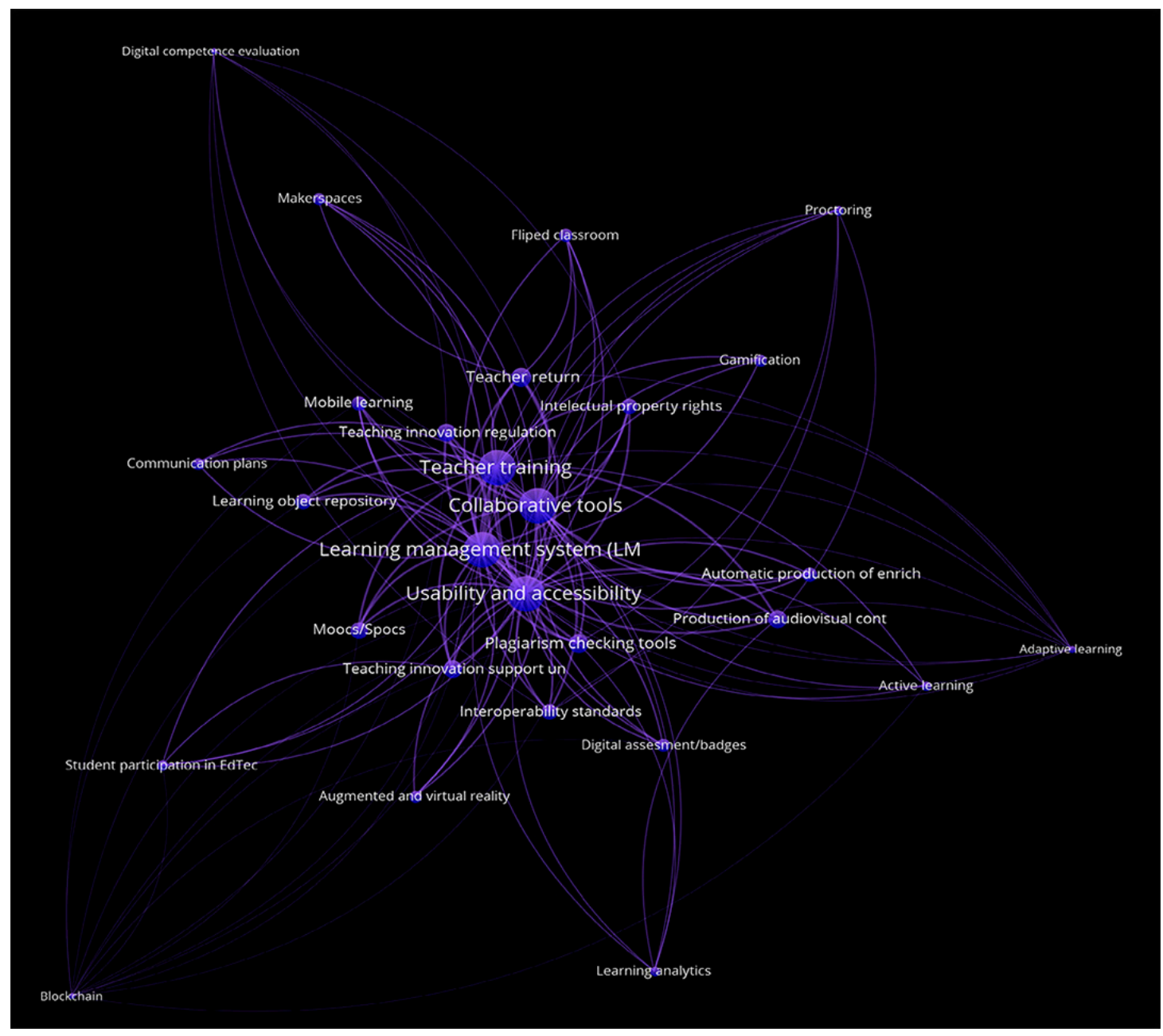

Fig. 2. EdTech Map. 
important aspects of the analyzed data such as local relations. The nodes associated with two technologies have a much closer spatial position when their adoption is more similar (i.e. when many universities have jointly adopted both technologies) at a global level. Thus, the distances between the nodes, determined by the layout algorithm to make them match the global network distances, intuitively represent the similarities and differences between the different EdTech topics depending on their adoption. There is a center-periphery effect according to which the technologies located in the central part have a more similar behavior to each other (they are mostly adopted). The technologies positioned at the ends of the map show very different behavior from those in the center (lower adoption values that are reduced as we move away from the center) and consequently, also different from each other in terms of joint adoption. For example, Adaptive learning and Active learning are currently minority technologies, as reflected by their presence at one end of the map and the small size of their nodes; but they behave similarly to each other, given their joint adoption with other technologies, since they are located very near each other on the map. In contrast, Blockchain also shows limited adoption but behaves differently with respect to the two former technologies (and the rest), being isolated and located at a different end of the map.

In view of the map, we can corroborate several of the conclusions reached in CRUE's FOLTE report (see [8]). The 11 topics of the technologies identified there as "well established" (Teacher training, Collaborative tools, Learning management system (LMS), Usability and accessibility, Teaching innovation regulation, MOOCs/SPOCs, Teaching innovation support unit, Plagiarism checking tools, Learning object repository, Teacher return, and Production of audiovisual contents) are located in the center of the map and show a large number of relations of joint adoption among them (large size of the nodes), indicating their importance in the network and their extent of adoption by Spain's universities. The spatial distribution of this central part indicates some segmentation in their importance, distinguishing two groups: one more focused with the six most important technologies (the first six mentioned), and another with the remaining five, seen to occupy a slightly lower level of importance by being a little further away from the center of the map. This also gives us a global idea of the relationship between technologies, since a close position on the map of a group of them indicates a greater joint adoption. The other three technologies located beyond the central zone of the map are Automatic production of enriched video, Intellectual property rights (IPR), and Mobile learning, which were classified in the second category in the report. Although they did not reach the adoption threshold of $70 \%$ required for the category of "well established", their position is appropriate given that they show fairly high penetration (almost 60\% the first, $57.6 \%$ the second, and $53.2 \%$ the third).

The analysis of the periphery of the map is also quite similar to the hierarchy detected in the report. Two of the three technologies identified in the "low interest" category, Digital competence evaluation and Blockchain, are clearly located at two of the ends of the map, their nodes furthest from the center and smallest in size. The other technologies with a very peripheral position are Learning analytics, Adaptive learning, Proctoring, Makerspaces, and Student Participation in EdTech plans. All of them are located in the third category, "incipient", in the report. The map permits a greater granularity in the differentiation of the global importance of the latter five technologies, depending on the distance to the center and the joint relations with the rest, reflected by the size of the node. Makerspaces and Student participation in EdTech plans are the two most important topics in the group according to these criteria.

Finally, the remaining technologies (Communication plans, Interoperability standards, Active learning, Flipped classroom,
Augmented and virtual reality, Digital assessment/badges to accredit learning, and Gamification) present an intermediate positioning, with different implementation levels depending on their distance to the center and the number of joint adoption relationships. This situation is well reflected in the map: the former three are more centered and have more relations of joint adoption than the latter three in all cases except Active learning. Although it has a good node size, it is more peripheral than the other two technologies of the second group. . This is because Active learning belongs to the second category, "in process", formed by the technologies where the union of the current adoption and the interest in a future adoption ("under study" response) is over a $60 \%$. Hence, its position in the map is essentially a consequence of the "under study" answers (41\%) rather than the "already adopted" ones (27.3\%). Since the designed map is based on affirmative answers, the position of the node is appropriate.

\section{B. Analysis of the Universities Map}

Fig. 3 reports the map of the network generated from the data of institutional interest that the 47 universities expressed in adopting the technologies of study. In this case, the pruned network PFNET $(r, q=n-1)$ has 136 links and $D=0.13$, as opposed to the 1049 links of the original network, with $D=0.97$.

Again, the map helps us draw a series of relevant conclusions. A direct link between two nodes indicates that those two universities share an interest in the adoption of a large number of common technologies. The presence of groups of nodes in the same area of the map and, above all, the presence of paths connecting them (the metaphor of the subway map) denotes that the universities show a strategic interest in the same technologies.

This map is seen to be more disperse than the one analyzed in the previous section, precisely because there is greater dispersion in the behaviors reflected. Logically, we find universities that decided to adopt more EdTech than others based on their strategic plans. Yet given the natural distinction between one's own technologies (for instance, Proctoring might hold, a priori, more strategic interest for on-line universities), the center of the map does not only contain the universities implementing more technologies (larger nodes). Rather, it may include others that, having adopted fewer, incorporated the ones that turned out to be the most widespread at the global level. This gives rise to a representative pattern (average strategic profile) of the decisions made by all the universities up to now.

Apart from providing an overall view of the situation, this strategic interest map also allows us to uncover interesting relation patterns between the decisions taken by the different universities. That can be done by identifying cohesive groups (communities) in the associated social network. This SNA task is usually developed in an automatic way using community detection methods [39]. However, in our case study we will take advantage of the fact that a highly interpretable situation map has been derived. The center-periphery effect represented in the map is useful to perform a manual analysis where the expert can lead the community detection process. We will thus consider both methodologies. First, a human expert analysis will be developed by focusing on the center of the map, where the universities adopting a larger number of technologies are located, and defining the groups according to the relations of the remaining universities to these central universities. The position of each university in the map, which is related with the global relations in the system, will be considered to define the soft boundaries between the groups, resulting in an interesting analysis. We will also develop an automatic community detection by means of the robust and recently proposed Leiden algorithm and will benchmark the obtained groupings with those identified in the expert analysis. 


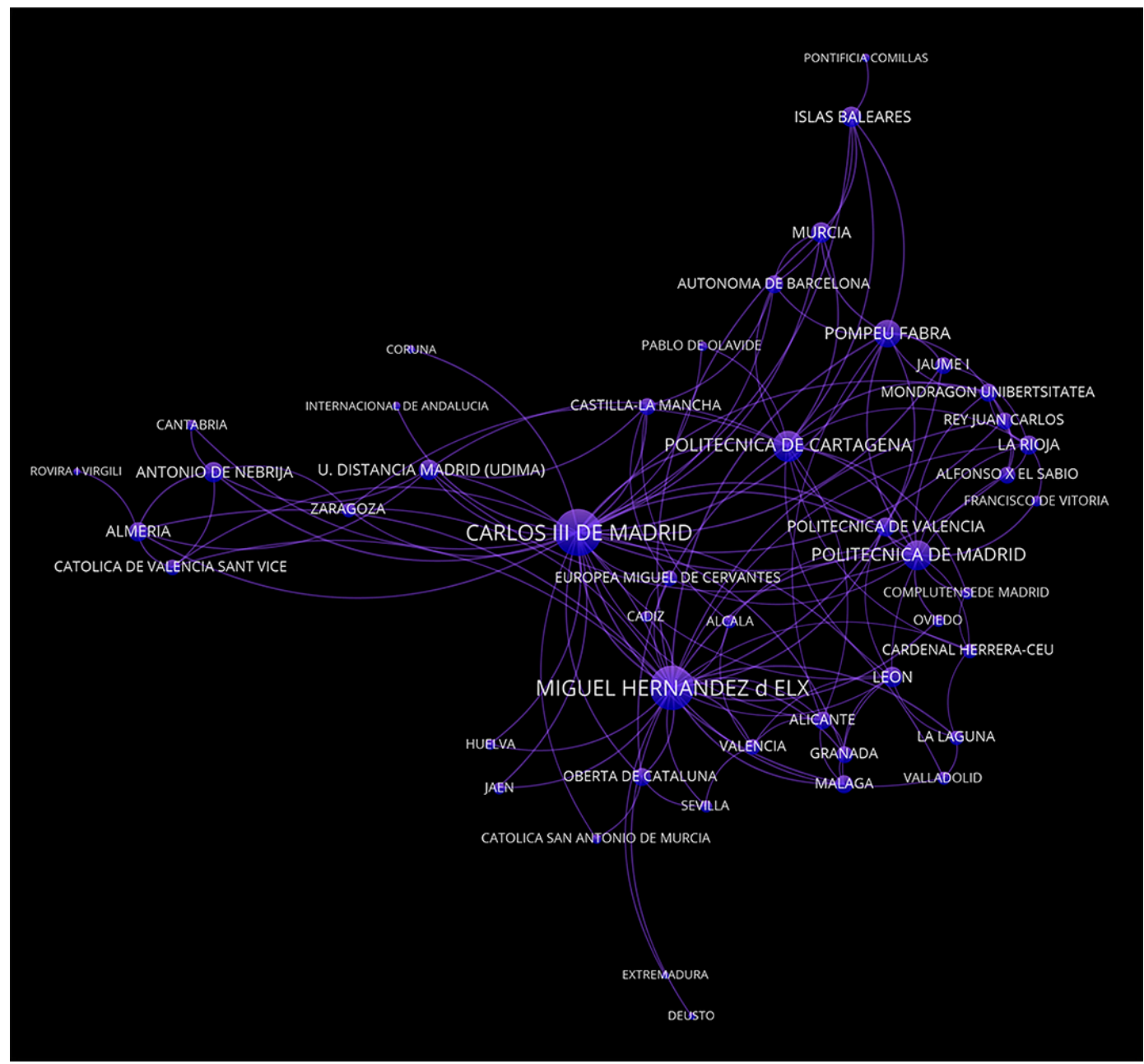

Fig. 3. Map of strategic interest of Spanish Universities in EdTech.

In the center of the map we have, on the one hand, a triangle formed by three universities that adopted many technologies: Carlos III de Madrid, Miguel Hernández d'Elx, and Politécnica de Cartagena. The fact that there are direct links forming this triangle means a high similarity in the chosen technologies. On the other hand, we have a series of universities that implemented fewer technologies, though some are different from the three main hubs. In this group we find: Politécnica de Madrid, Politécnica de Valencia, Europea Miguel de Cervantes, Alcalá, and Cádiz. The Europea Miguel de Cervantes university is the only one that shares links with all three hubs, indicating that despite its limited introduction of technologies (note small node size), the chosen technologies are shared with those of the three most central universities. The remaining institutions only have links to two (Politécnica de Valencia) or one (Politécnica de Madrid, Alcalá, and Cádiz) of them. This is interpreted as the average behavior (hence the central position on the map), but indicative of similarities and differences in the strategic adoption profile depending on which university they are linked to.

Moving from the center to the periphery, we may discern four large groups in the four cardinal directions, some more clearly clustered than others. To clarify these modularity relations, Fig. 4 presents the same map as Fig. 3, but highlighting in different colors the five groups of universities according to their strategic interest in adopting EdTech in Spain. The central group, depicted in blue, has already been analyzed. The other four clusters are described below. In addition to showing the internal cohesion of the groups, the inner links (i.e. those linking two universities from the same group) are seen in the group color, whereas the outer links show a blended color between the two group colors of the nodes they link.

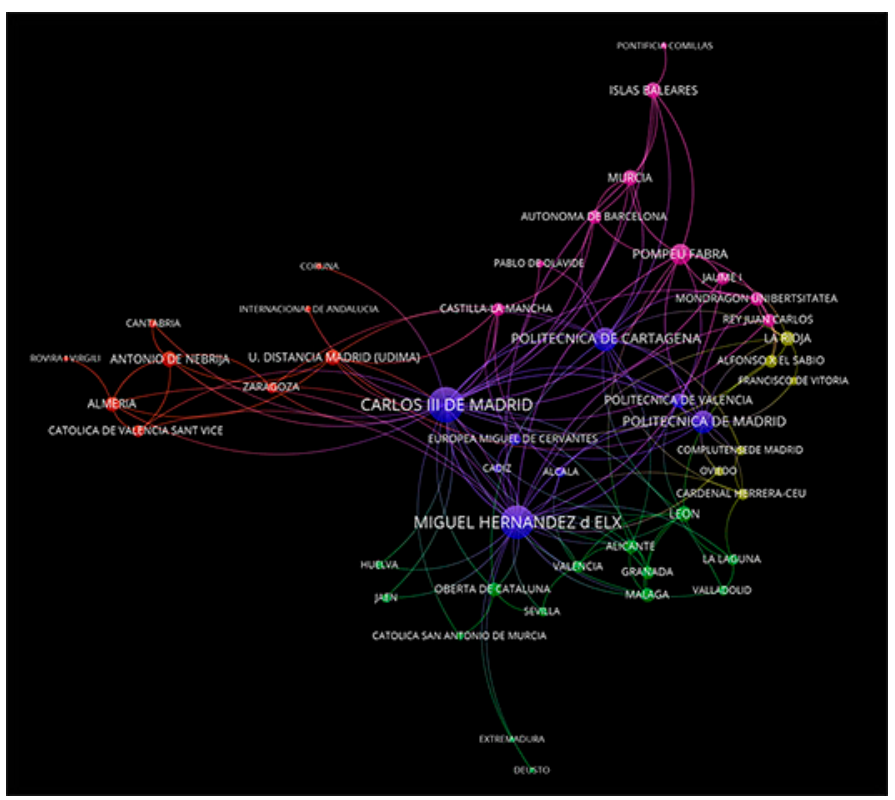

Fig. 4. Expert partitioned map of strategic interest of Spanish Universities in EdTech. 
Possibly the cluster that is most easily identified is the one to the left or "west", formed by the Universities of Coruña, Internacional de Andalucía, UDIMA, Zaragoza, Cantabria, Antonio de Nebrija, Almería, Católica de Valencia Sant Vicent, and Rovira $i$ Virgili. The nodes and inner links of these universities are depicted in red. They share technologies with each other as well as with Carlos III de Madrid, the central node that has the most connections with this group. Local relations permit the identification of patterns of similar strategic interest profiles, e.g. those of Universidad Antonio de Nebrija with four of the universities in the group. Indeed, we identified a new triangle between the Antonio de Nebrija, Almería, and UDIMA universities, the three largest nodes in the group.

Fig. 5 depicts the specific subgraph of universities in this cluster for the sake of clarity. It illustrates the strong cohesion of the group; even upon the removal of the most influential binding node of the center group, Carlos III de Madrid university, the group still keeps connected to all but two nodes. These two universities, Coruña and Internacional de Andalucía, become isolated, being linked only to the influential node. (We must keep in mind that the Pathfinder network preserves only the most salient relations in the original network after pruning).

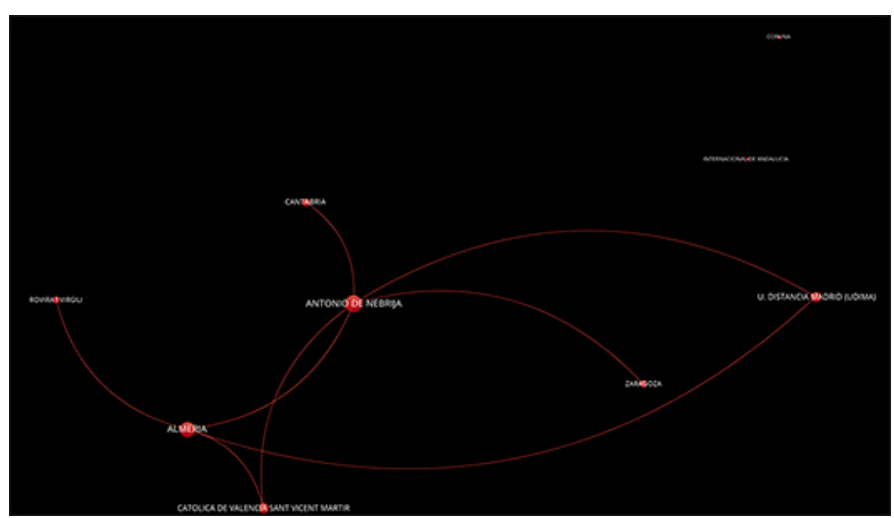

Fig. 5. "West" group of universities.

The next group identified is the "southern" sector of the map, shown in green. It includes the Universities of Huelva, Jaén, Oberta de Catalunya, Sevilla, Católica San Antonio de Murcia, Extremadura, Deusto, Valencia, Alicante, Granada, Málaga, León, La Laguna, and Valladolid. In this case, in addition to sharing technologies with each other, they share them principally with Universidad Miguel Hernández d'Elx. We spot two triangles between the Universities of Valencia, Alicante, and Granada, on the one hand, and Alicante, Granada, and Málaga, on the other. They show very similar profiles in terms of both the triple relation and the spatial proximity, hence the number of technologies adopted (the same, given the size of the nodes).

From a general perspective, this "southern" group has a more diverse and less cohesive behavior than the "western" group (note the diversity of relations with the main nodes in the center of the map). Fig. 6 highlights the part of the map where this can be clearly seen. Two subgroups of pairs of universities are not linked to the major component of the group: Huelva plus faén on the left, and Extremadura and Deusto beneath. In both cases this is because the most salient relations of these four universities are associated only with the central nodes, strongly related with them. Whereas Extremadura and Deusto are only linked to Miguel Hernández d'Elx, the influential central node of this group, Huelva and Jaén are also linked to Carlos III de Madrid. This justifies their spatial separation in the map with respect to the remaining nodes in the group.

Third, we can identify an analogous group in the upper, "northern" part of the map, represented in pink. The profiles of strategic interest

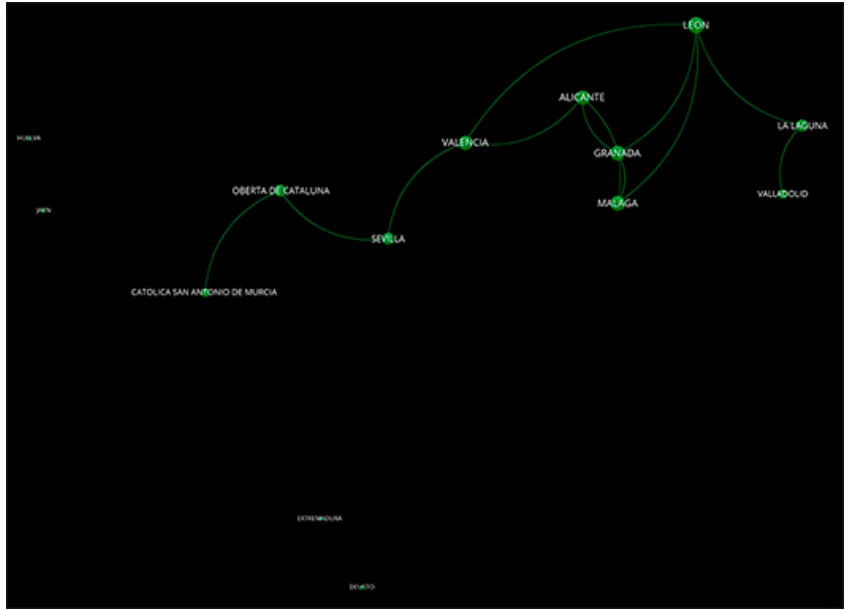

Fig. 6. "South" group of universities.

in EdTech of the universities that compose it are related to those of two universities of the main nodes, Carlos III de Madrid and Politécnica of Cartagena. Those located more to the left are related particularly to the former, those more to the right with the latter, and those of the central part with both to an equal extent. The borders of this third group are fuzzier on the right, given that the universities located in that area also have strong relations with other nodes in the center of the map such as those of the Technical Universities of Madrid and Valencia. This group basically includes the universities of Castilla-La Mancha, Pablo de Olavide, Autónoma de Barcelona, Murcia, Islas Baleares, Pontificia de Comillas, Pompeu Fabra, Jaume I, Mondragón Unibertsitatea, and Rey fuan Carlos, although it is difficult to draw a border or division in the right part of the group, where more cross-relations are found. There is no triangle formed only by nodes of the universities in the group. All of the above allows us to conclude that this "northern" group features the greatest diversity of strategic profiles regarding Edtech adoption.

Fig. 7 shows the north subgraph of universities. Despite the diverse behavior analyzed in the former paragraph, due to the different relational patterns involving the central nodes, this figure highlights the strong cohesion existing between the universities of the group. Only Pablo de Olavide University is disconnected, having just two direct links to the two influential nodes, Carlos III de Madrid and Politécnica of Cartagena.

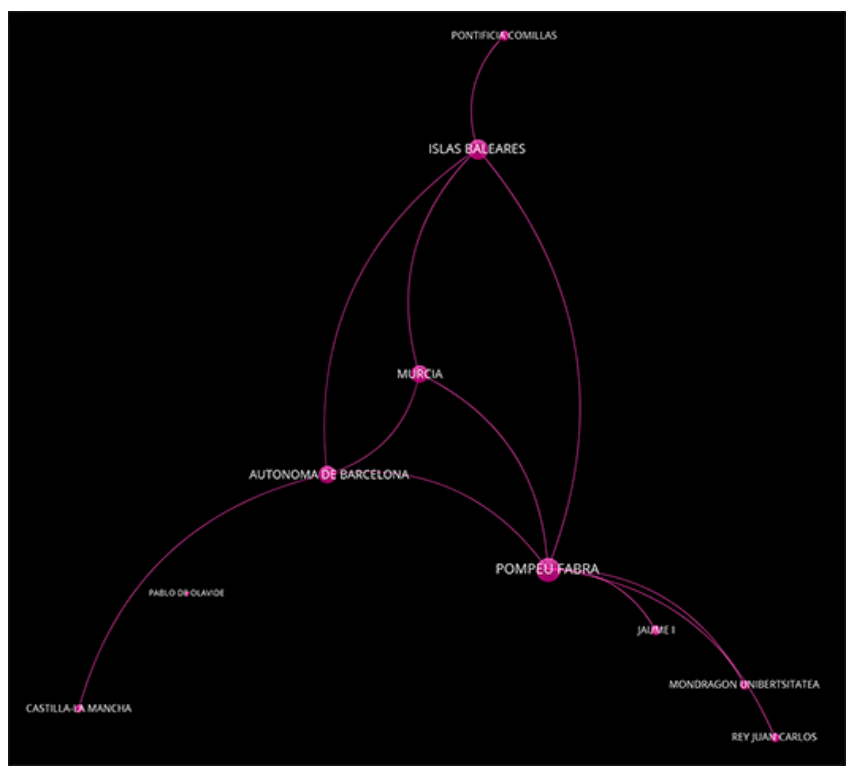

Fig. 7. "North" group of universities. 
Finally, the fourth group is located to the "east", colored yellow, and its borders are the least distinct. We consider it to contain La Rioja, Alfonso X el Sabio, Francisco de Vitoria, Complutense de Madrid, Oviedo, and Cardenal Herrera-CEU universities. Their relations indicate that overall their strategic profile is similar to that of Universidad Miguel Hernández d'Elx, though some are also directly related to the Universidad Politécnica de Madrid and there are moreover links to other nodes in the center of the map. Again, no triangles are formed by this grouping.

Fig. 8 renders the final subgroup and provides additional information supporting the conclusions already drawn. When the central nodes are removed, three small subgroups can be distinguished, with the least cohesive behavior among all five of the groups analyzed. $L a$ Rioja, Alfonso X el Sabio, and Francisco de Vitoria are linked to four different nodes in the central part: Carlos III de Madrid, Miguel Hernández d'Elx, Politécnica de Cartagena, and Politécnica de Madrid. Politécnica de Madrid is the only one shared, between Alfonso $X$ el Sabio and Francisco de Vitoria. This signals the three universities in this subgroup as gateway nodes sharing an intermediate EdTech adoption pattern. Meanwhile, Complutense de Madrid and Cardenal Herrera-CEU share a link, but their most salient relations to the central nodes are different -Complutense de Madrid to Politécnica de Madrid, and Cardenal Herrera-CEU to Miguel Hernández d'Elx. Hence, a similar case of gateway nodes. Lastly, Oviedo is isolated because its two main relations are specifically to these two central nodes, Politécnica de Madrid and Cardenal Herrera-CEU, thus tracing a slightly different interest pattern than the former two, and no link to either.

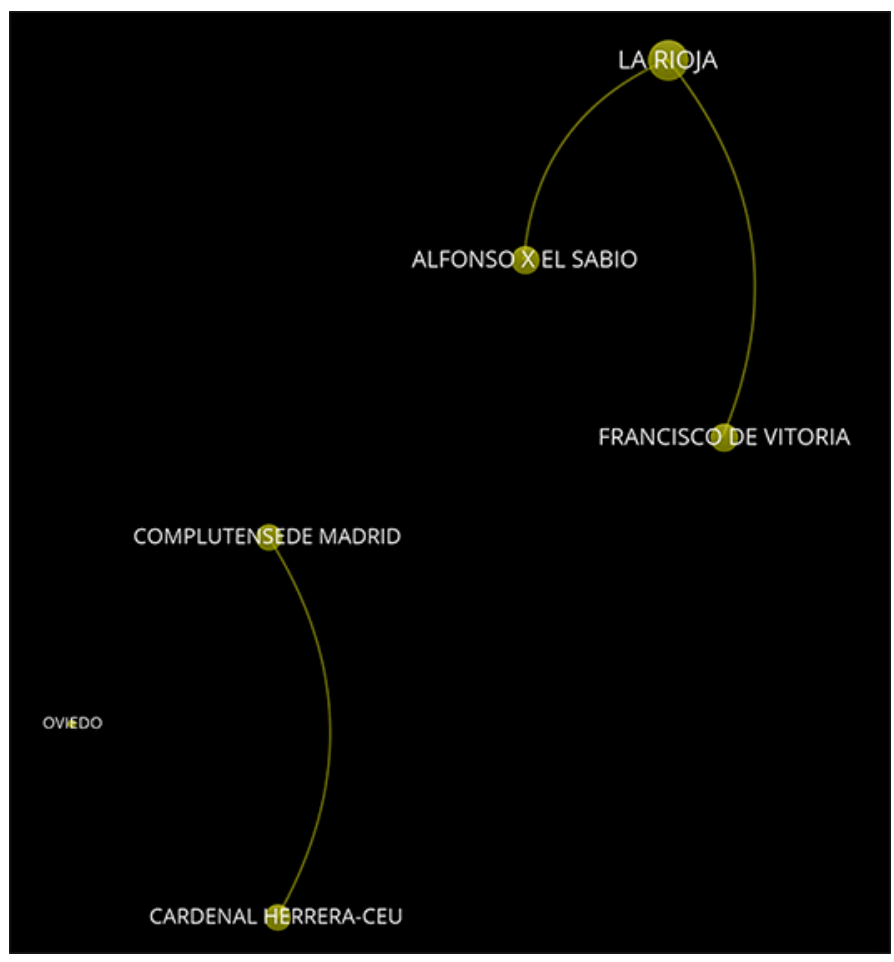

Fig. 8. "East" group of universities.

Once the expert analysis have been developed, we will validate it through automatic community detection. The Leiden algorithm has been applied setting different values for the resolution parameter in order to derive an optimal partition for different number of communities. We have considered three different number of communities, from two (which provided the optimal partition in terms of modularity) to four (which is the most similar number to that considered in the expert analysis, as we will see below). Table
II collects the statistics (modularity value and number/distribution of communities) for each partition while Fig. 9 to Fig. 11 depict the different partitions in the institutional interest map.

TABLE II. Statistics of the Different Partitions Derived By the Leiden Algorithm

\begin{tabular}{|c|c|c|c|c|c|}
\hline \#Com. & Modularity & $\begin{array}{c}\text { \% and \# } \\
\text { nodes Com. } \\
\mathbf{1}\end{array}$ & $\begin{array}{c}\text { \% and \# } \\
\text { nodes Com. } \\
\mathbf{2}\end{array}$ & $\begin{array}{c}\text { \% and \# } \\
\text { nodes Com. } \\
\mathbf{3}\end{array}$ & $\begin{array}{c}\text { \% and \# } \\
\text { nodes Com. } \\
\mathbf{4}\end{array}$ \\
\hline 2 & 0,415 & $55,32 \%(26)$ & $44,68 \%(21)$ & ----- & ---- \\
\hline 3 & 0,381 & $34,04 \%(16)$ & $34,04 \%(16)$ & $31,91 \%(15)$ & ---- \\
\hline 4 & 0,313 & $31,91 \%(15)$ & $29,79 \%(14)$ & $25,53 \%(12)$ & $12,77 \%(6)$ \\
\hline
\end{tabular}

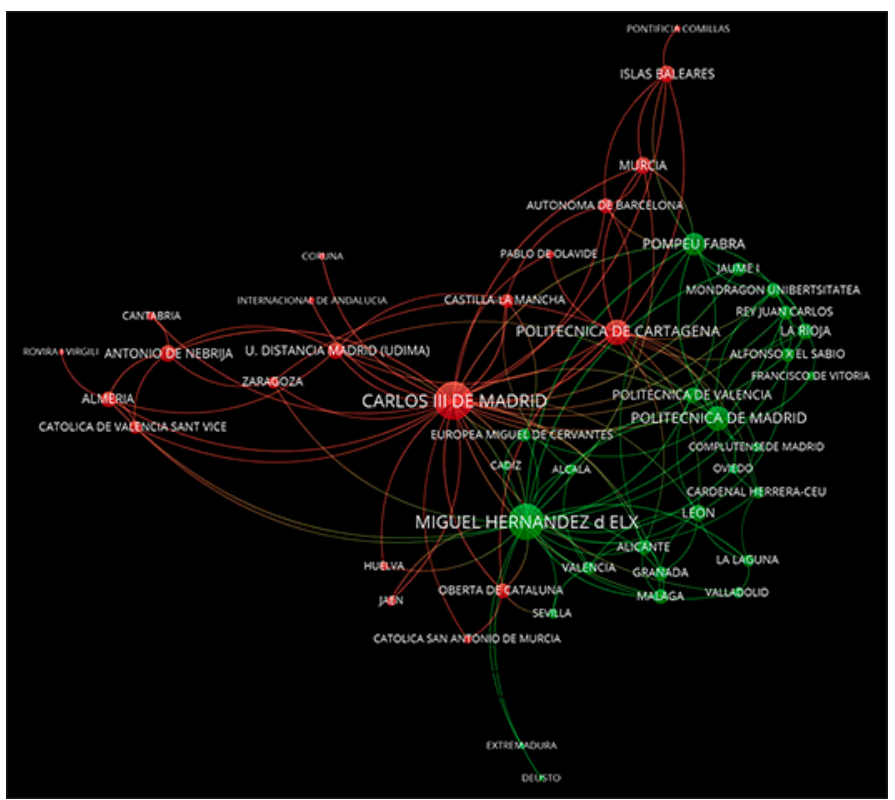

Fig. 9. Automatically partitioned map of strategic interest of Spanish Universities in EdTech: Leiden with 2 partitions.

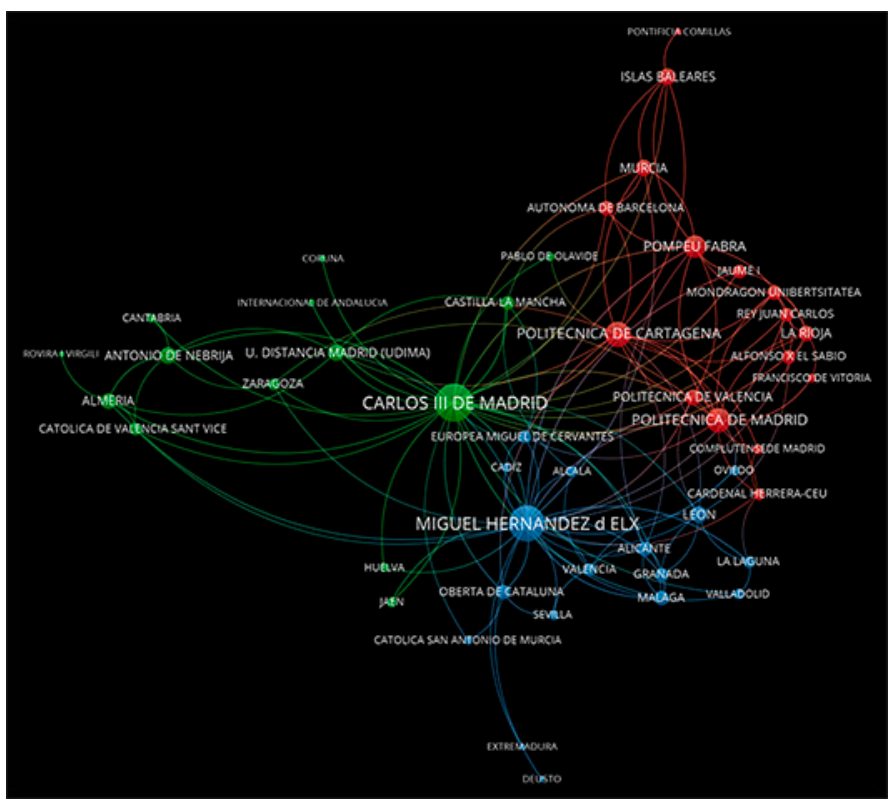

Fig. 10. Automatically partitioned map of strategic interest of Spanish Universities in EdTech: Leiden with 3 partitions. 


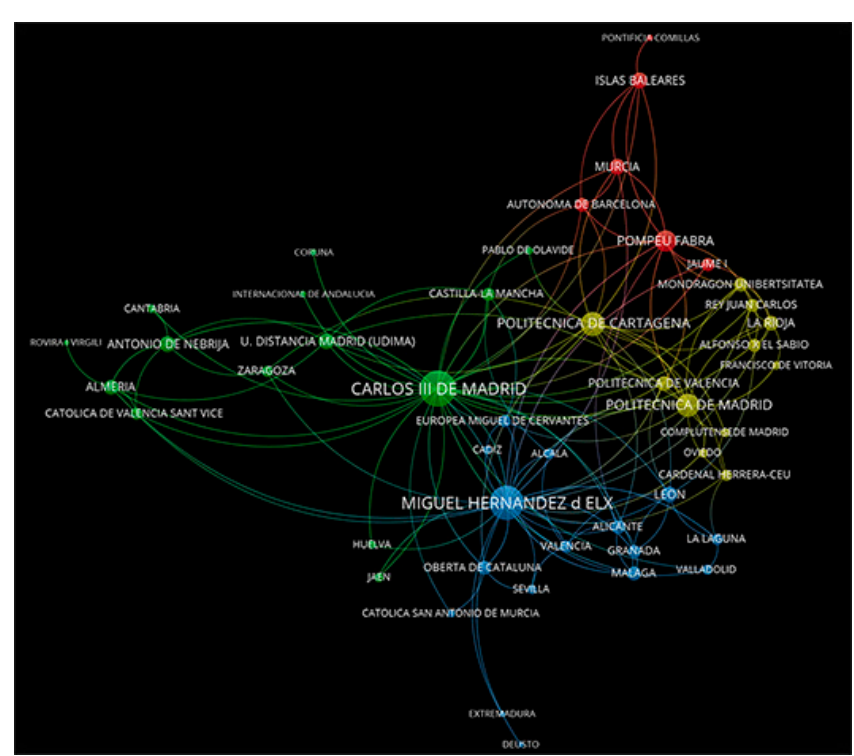

Fig. 11. Automatically partitioned map of strategic interest of Spanish Universities in EdTech: Leiden with 4 partitions.

The three partitions chosen can be considered reasonable as the modularity values are over the usual 0.3 threshold considered in the area [42]. The modularity value increases with the reduction of the number of communities. The partition with two communities shows the best value, 0,415 . The main differences between the automatic and the manual partitioning is of course the fact that the nodes associated to the universities located in the center of the map were grouped in a specific community in the manual partitioning. That was done to get a single group corresponding to the universities with the highest strategic interest in EdTech adoption for the expert analysis. Then, the remaining four communities were derived from their relation to the three most central universities as defined by their positions in the map. Alternatively, automatic community detection directly creates the communities by grouping those central nodes to the most related nodes, i.e., universities having a common adoption of the different technologies, as expected.

The good performance of the map generation methodology when locating the most active universities in the center, the less active ones in the periphery, and universities sharing a similar strategic interest on EdTech spatially close can be corroborated by analyzing the composition of the groups. Note that, as soon as three different groups arise, each of them includes one of the three most central universities (Carlos III de Madrid, Miguel Hernández d'Elx, and Politécnica de Cartagena). Hence, the visualization methodology allows the information analyst to identify the inherent global relations at first sight. We can also notice that the partition with four communities is very similar to the one identified in the expert analysis (apart from the fact that in the latter a central group was voluntarily identified). Only some nodes located in the border between two different communities and with a few links to nodes in different communities are grouped in a different way (Católica San Antonio de Murcia, Huelva, Castilla La Mancha, Pablo de Olavide, ...). This again reinforces the good spatial properties of the visualization to achieve an informative representation of the analyzed domain.

Finally, note that Carlos III de Madrid and Politécnica de Cartagena universities are most similar in their EdTech adoption strategies than Miguel Hernández d'Elx university, as shown by the best partition obtained by the Leiden community detection method. This partition, composed of only two communities, groups the former two in the same community and provides us with the largest aggregation of strategic adoption plans in the SUS.

\section{Conclusions}

The current challenges surrounding Covid-19 are not limited to the realm of Medicine. They likewise require responses from all types of professionals, to meet a range of training needs at the core of pandemic-related priorities. The current contribution aims to visually present the situation of EdTech adoption in the SUS based on data from the survey carried out by the FOLTE Group for the CRUE TIC report [8]. We designed two different maps to respectively depict the penetration of different types of technologies in the SUS, and the strategic interest of the universities in their adoption. Our goal was to facilitate both an overall grasp as well as detailed analysis of the relations among the different technologies/universities. The maps created are easy to interpret, by looking at the distribution and spatial localization of the corresponding nodes.

The first map corroborates several of the conclusions drawn from the report, although the visual information is more granular, making it easier to distinguish the global importance of the technologies. Such additional insights depend on the distance to the center and the joint relations with the rest, reflected by the size of the nodes. The 11 topics of the most implemented EdTech topics occupy the center of the map, whose spatial distribution leads us to conclude that the six most adopted technologies are Teacher Training, Collaborative Tools, LMS, Usability and Accessibility, Teaching innovation regulations, and MOOCs/SPOCs. The two most peripheral technologies and therefore the least widespread ones are Digital competence evaluation and Blockchain.

The second map allows us to study the positioning of the different Spanish universities according to the strategic decisions made about adopting EdTech to date. Based on this map we may uncover similarities and differences, as well as identify general and specific profiles in the corresponding decision-making processes at the institutional level. The center of the map is not only composed of universities that have implemented more technologies; it likewise includes ones that, having adopted less, have incorporated precisely those most widespread at the global level. This gives rise to a representative pattern (an average strategic profile) of the relevant decisions made by all the universities until now. Moving from the center to the periphery, we can identify four large groups of universities in the four cardinal directions - some more clearly differentiated than others- depending on the similarity of the strategies applied for the adoption of technologies. That is very relevant information, pointing to similar and differential behaviors.

We should note that the maps generated are capable of showing the situation of EdTech in a full university system in a single visual representation. This makes them a powerful analytical tool for professors, researchers, and university managers involved in decisionmaking; indeed, they can serve as the support system requested by researchers and specialized journals [43]. In particular, the latter group can take advantage of these representations to support their strategic decisions related to the adoption of EdTech in their institutions. In addition to specific insights regarding the SUS brought out in the current manuscript, the proposed methodology can be directly applied to other university systems from different countries in the future. This would allow analysts to acquire additional knowledge about their own system and compare their situation to that of other countries. What is more, it can be applied to analyze evolution patterns by generating consecutive maps in different time periods. That is extremely interesting as the FOLTE group is currently developing a new report for CRUE that collects data on the current situation after the appearance of the Covid-19 crisis. Hence, post-pandemic maps can be generated and compared to those presented in this contribution in the future. Given that there has been a strong development of EdTech in the SUS as a consequence of the actions developed by the different 
Spanish universities to face the negative effects of the pandemic, this comparison would be extremely interesting.

\section{ACKNOWLEDGMENT}

The authors would like to express their special thanks to the Working Group in Online Training and Educational Technologies (FOLTE), of the ICT Sectorial of the Commission of Rectors of Spanish Universities (the Spanish University Association, CRUE Universidades Españolas). Moreover, this work was supported by the Spanish Ministry of Science, Innovation and Universities, and ERDF under grant EXASOCO (PGC2018-101216-B-I00).

\section{REFERENCES}

[1] T. J. Newby, D. Stepich, J. Lehman, J. D. Russell, and A.T. Leftwich, Educational Technology for Teaching and Learning, 4th ed., New York: Pearson, 2010.

[2] T. Gray and H. Silver-Pacuilla, Eds., Breakthrough teaching and learning: how educational and assistive technologies are driving innovation, New York: Springer-Verlag, 2011.

[3] B. Alexander, et al., "EDUCAUSE Horizon Report: 2019 Higher Education Edition", Louisville, CO: EDUCAUSE, 2019.

[4] R. Ferguson, et al., "Innovating pedagogy 2017: Open university innovation report \#6", Milton Keynes: The Open University, 2019. Accessed: Feb. 06, 2021. [Online]. Available: https://iet.open.ac.uk/file/ innovating-pedagogy-2017.pdf.

[5] J-M. Lowendahl, T-L. Thayer, and G. Morgan. "Top 10 strategic technologies impacting higher education in 2016". Accessed: Feb. 06, 2021. [Online]. Available: https://www.gartner.com/en/documents/3186323/ top-10-strategic-technologies-impacting-higher-education.

[6] J. King, and J. South. "Reimagining the Role of Technology in Higher Education. A Supplement to the National Education Technology Plan", Washington: U.S. Department of Education, Office of Educational Technology, 2019. Accessed: Feb. 06, 2021. [Online]. Available: https:// tech.ed.gov/files/2017/01/Higher-Ed-NETP.pdf.

[7] R. Walker, et al. "Survey of technology enhanced learning for higher education in the UK", Oxford: Universities and Colleges Information Systems Association, 2016. Accessed: Feb. 06, 2021. [Online]. Available: https://www.ucisa.ac.uk/bestpractice/surveys/tel/tel.aspx

[8] J. Gómez Ortega, et al. "Informe de situación de las Tecnologías Educativas en las universidades españolas 2018" (in Spanish). Madrid: Crue Universidades Españolas, 2019. Accessed: Feb. 06, 2021. [Online]. Available: https://tic.crue.org/publicaciones/\#folte.

[9] S. Wasserman, and K. Faust, Social network analysis: methods and applications (structural analysis in the social sciences), Cambridge: University Press, 1994.

[10] A. Santos, et al., "Estado de situación de las Tecnologías Aplicadas a la enseñanza y el aprendizaje en la Educación Superior argentina" (in Spanish). Buenos Aires: Metared, 2019, Accessed: Feb. 10, 2021. [Online]. Available: https://www.metared.org/argentina/wp-content/uploads/ sites/11/2019/10/Estado-de-Situacion-TAEA-Educacion-Superior Metared-Argentina.pdf.

[11] J. L. Ponce-López, C. M. Vicario-Solórzano, and F. López-Valencia. "Estado Actual de las Tecnologías Educativas en las Instituciones de Educación Superior en México" (in Spanish). ANUIES, México, 2021. Accessed: Feb. 21, 2021. [Online]. Available: https://estudio-tic.anuies.mx/\#estado_te.

[12] M. Miller, Ditch That Textbook: Free Your Teaching and Revolutionize Your Classroom, Michigan: Dave Burgess Consulting, 2015.

[13] P. A. Rodríguez, V. Tabares, N. D. Duque, D. A. Ovalle, and R. M. Vicari, "BROA: An agent-based model to recommend relevant Learning Objects from Repository Federations adapted to learner profile", International fournal of Interactive Multimedia and Artificial Intelligence, vol. 2, no. 1, pp. 6-11, 2013, doi:10.9781/ijimai.2013.211.

[14] G. Allen. The New Pillars of Modern Teaching, Bloomington: Solution Tree Press, 2016.

[15] L. Kolb. Learning First, Technology Second: The Educator's Guide to Designing Authentic Lessons, Portland, Oregon: International Society for Technology Education, 2017.
[16] L. De-Marcos, E. García-Lopez, A., and García-Cabot. "On the effectiveness of game-like and social approaches in learning: Comparing educational gaming, gamification \& social networking", Computers \& Education, vol. 95, pp. 99-113, 2016, doi:10.1016/j.compedu.2015.12.008.

[17] J. Nouri. "The flipped classroom: for active, effective and increased learning - especially for low achievers", International fournal of Educational Technology in Higher Education, vol. 13, no. 33, 2016, doi: 10.1186/s41239-016-0032-z.

[18] Á. Martínez Navarro and P. Moreno-Ger. "Comparison of clustering algorithms for learning analytics with educational datasets", International Journal of Interactive Multimedia and Artificial Intelligence, vol. 5, no. 2, pp. 9-16, 2018, doi: 10.9781/ijimai.2018.02.003.

[19] R. Klamma, P. de Lange, A.T. Neumann, and P. Nicolaescu, "An Integrated Learning Analytics Approach for Virtual Vocational Training Centers", International Journal of Interactive Multimedia and Artificial Intelligence, vol. 5, no. 2, pp. 32-38, 2018, doi:10.9781/ijimai.2018.02.006.

[20] J. M. Spector, "Remarks on MOOCS and Mini-MOOCS", Educational Technology Research and Development, vol. 62, no. 3, pp. 385-392, 2014.

[21] S. Margoum, R. Bendaoud, K. Berrada, and A. Idrissi. "UC@MOOC's Effectiveness by Producing Open Educational Resources", International Journal of Interactive Multimedia And Artificial Intelligence, vol. 5, no. 2, pp. 58-62, 2018, doi:10.9781/ijimai.2018.02.007.

[22] J. Gómez Ortega, et al., "UNIVERSITIC 2017, Análisis de las TIC en las universidades españolas" (in Spanish). Madrid: Crue Universidades Españolas, 2017. Accessed: Feb. 06, 2021. [Online]. Available: http://tic. crue.org/publicaciones/informe-universitic-2017.

[23] M. Koehler, and P. Mishra, "What is technological pedagogical content knowledge (TPACK)?" Contemporary Issues in Technology and Teacher Education, vol. 9, no 1, pp. 60-70, 2009.

[24] D. P. Pancho, J. M. Alonso, O. Cordón. A. Quirin and L. Magdalena. "FINGRAMS: visual representations of fuzzy rule-based inference for expert analysis of comprehensibility", IEEE Transactions on Fuzzy Systems, vol. 21, no 6, pp. 1133-1149. 2013.

[25] E. Serrano, A. Quirin, J. Botia, and O. Cordón, "Debugging complex software systems by means of pathfinder networks", Information Sciences, vol. 180, no 5, pp. 561-583, 2010.

[26] Trawinski, M. Chica, D. Pancho, S. Damas, and O. Cordón, "moGrams: a network-based methodology for visualizing the set of non-dominated solutions in multiobjective optimization", IEEE Transactions on Cybernetics., vol. 48, no 2, pp. 474-485, 2018.

[27] C. Zarco, C. E. Santos, and O. Cordón, "Advanced visualization of Twitter data for its analysis as a communication channel in traditional companies", Progress in Artificial Intelligence, vol. 8, no 3, pp. 327-333, 2019.

[28] B. Vargas-Quesada, Z. Chinchilla-Rodríguez, and N. Rodriguez, "Identification and visualization of the intellectual structure in graphene research", Frontiers. Research. Metrics. Analytics, vol. 2, no 7. 2017. Accessed: Feb. 06, 2021. [Online]. Available: https://doi.org/10.3389/ frma.2018.00013.

[29] A. Quirin, O. Cordón, J. Santamaría, B. Vargas-Quesada, and F. MoyaAnegón, "A new variant of the pathfinder algorithm to generate large visual science maps in cubic time", Information Processing \& Management, vol. 44, no 4, pp. 1611-1623, 2008.

[30] X. Lin, H. D. X. White, and J. Buzydlowski, J. "Real-time author cocitation mapping for online searching", Information Processing \& Management, vol 39, no. 5, pp. 689-706. 2003, doi.org/10.1016/S03064573(02)00037-7

[31] N. J. van Eck, and L. Waltman, L. "Visualizing bibliometric networks", In Y. Ding, R. Rousseau, \& D. Wolfram (Eds.), Measuring scholarly impact: Methods and practice, pp. 285-320. Springer, 2018.

[32] Author 3, 2008.

[33] T. Kamada, and S. Kawai, "An algorithm for drawing general undirected graphs”, Information Processing Letters, vol. 31, no 1, pp. 7-15. 1989.

[34] A. Unwin, M. Theus, and H. Hofmann, Graphics of large datasets: visualizing a million, New York: Springer Science \& Business Media, 2008.

[35] C. Chen, and S., "Visualizing evolving networks: Minimum spanning trees versus pathfinder networks", in Proceedings of IEEE Symposium on Information Visualization, Seattle, USA, pp. 67-74, 2003, doi:10.1109/ INFVIS.2003.1249010. 
[36] R. Schvaneveldt, F. Durso, and D. Dearholt, "Network structures in proximity data", Psychology of Learning and Motivation, vol. 24, pp. 249284. 1989.

[37] S. P. Borgatti, and M. G. Everett, "Models of core/periphery structures", Social Networks, vol. 21, no 4, pp. 375-395, 1999.kk

[38] N. J. Van Eck, and L. Waltman. "Software survey: VOSviewer, a computer program for bibliometric mapping”, Scientometrics, vol. 84, no 2, pp. 523538. 2010.

[39] S. Fortunato. "Community detection in graphs". Physics Reports, vol. 486, no 3-5, pp. 75-174, 2010, doi: 10.1016/j.physrep.2009.11.002.

[40] V. D. Blondel, J. L. Guillaume, R. Lambiotte, and E. Lefebvre. "Fast unfolding of communities in large networks". Journal of Statistical Mechanics: Theory and Experiment, vol. 10:10008, 2008, doi:10.1088/17425468/2008/10/P10008.

[41] V. A. Traag, L. Waltman, and N. J. van Eck. "From Louvain to Leiden: guaranteeing well-connected communities". Scientific Reports, vol. 9: 5233, 2019, doi:10.1038/s41598-019-41695-z.

[42] A. Clauset, M. E. J. Newman, and C. Moore. "Finding community structure in very large networks". Physical Review E, vol. 70:066111, 2004, doi: 10.1103/PhysRevE.70.066111.

[43] C. Romero, and S. Ventura, "Guest Editorial: Special Issue on Early Prediction and Supporting of Learning Performance", IEEE Transactions on Learning Technologies, vol. 12, no. 2, pp. 145-147, 2019, doi:10.1109/ TLT.2019.2908106

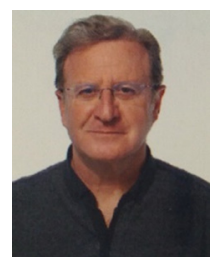

Benjamín Vargas-Quesada

Benjamín Vargas-Quesada obtained his Ph.D. degree in Scientific Library Science and Information from the University of Granada (UGR), Spain, in 2005. He is a Professor and the Dean of the Faculty of Communication and Library Science at the University of Granada, as well as a founding member of the SCImago group. His lines of research focus on information visualization, scientometric analysis of different scientific domains (geographic and disciplinary), and the analysis of networks of scientific collaboration, having published more than 100 peer-reviewed scientific publications -including a research book on information visualization, two book chapters on the same subject, and 38 JCR$\mathrm{SCI} / \mathrm{SSCI}$-indexed journal papers 26 in Q1- and having directed five Ph.D. dissertations and participated in 15 research projects and contracts (amounting to $\sim 2 \mathrm{M} €$ overall). As of January 2021, his publications received 758 citations (h-index=14) in the Clarivate Analytics' Web of Science, and 2943 citations and h-index $=27$ according to Google Scholar.

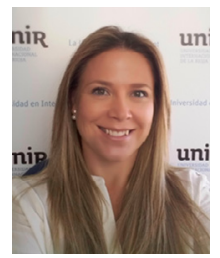

Carmen Zarco

Carmen Zarco is currently an Associate Professor at the International University of La Rioja (UNIR), Spain. She joined UNIR in 2013 and coordinated the Master on Digital Marketing and e-Commerce for two years (201516). Before, she was the responsible of the knowledge management unit at the European Centre for Soft Computing (2007-2011) where she was the link between the different research units and the support and management staff. In her professional career, she has enjoyed different positions of responsibility in private companies while combining such activity with research and teaching. She first had a research scholarship in Baratz, S.A. Teledocumentation Services (1999), was the documentation head at the pulevasalud.com health web portal (1999-2003), and was later promoted as responsible for the Knowledge Management unit in the Puleva Food, S.L. business (2003-2006). In her research career she has published several journal articles (some of them in journals indexed in the JCR), book chapters, and contributions to national and international conferences. She has also participated in different research projects and contracts. Her main research lines are related to information retrieval, communication management, and marketing analysis using tools based on artificial intelligence and social network analysis.

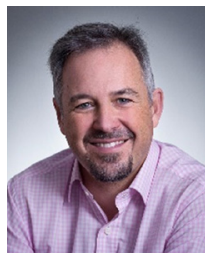

\section{Oscar Cordón}

Oscar Cordón is Professor with the University of Granada (UGR), Spain. He was the founder and leader of its Virtual Learning Center (2001-05) and Vice-President for Digital University (2015-19). He also was one of the founding researchers of the European Centre for Soft Computing (2006-2011), being later contracted as Distinguished Affiliated Researcher (2011-15). He has been, for almost 30 years, an internationally recognized contributor to R\&D Programs in fundamentals and real-world applications of computational intelligence. $\mathrm{He}$ has published more than 380 peer-reviewed scientific publications including a research book on genetic fuzzy systems (with $\sim 1400$ citations in Google Scholar) and 110 JCR-SCI-indexed journal papers (66 in Q1, 37 in D1), advised $19 \mathrm{Ph} . D$. dissertations, and coordinated 23 research projects and 15 research contracts (with an overall amount of $>9 \mathrm{M} €$ ). By February 2021, his publications had received 5357 citations (h-index $=39$ ), being included in the $1 \%$ of mostcited researchers in the world (source: Clarivate Analytics' Web of Science. 14427 citations and h-index $=57$ in Google Scholar). Besides, he is co-inventor of an international patent on an intelligent system for forensic identification under exploitation by Panacea Cooperative Research, distributed in Mexico and South Africa. He has developed intelligent marketing models with Zio Analytics for big brands as The Coca Cola Company, Jaguar-Land Rover L'Oréal Mexico, Samsung, Telefónica, and El Corte Inglés. Prof. Cordón received the UGR Young Researcher Career Award in 2004; the IEEE Computational Intelligence Society (CIS) Outstanding Early Career Award in 2011 (the first such award conferred); the International Fuzzy Systems Association (IFSA) Award for Outstanding Applications of Fuzzy Technology in 2011; the National Award on Computer Science ARITMEL by the Spanish Computer Science Scientific Society in 2014; the IEEE Fellow grade for his contributions to genetic and evolutionary fuzzy systems in 2018; and the IFSA Fellow in 2019. He also was a member of the Working Group that developed the Spanish R+D Strategy for Artificial Intelligence by the Spanish Ministry of Science (2018-19). He was member of the ICT Executive Board of the Association of Spanish Universities and President of the Working Group on Online Learning and Educational Technologies (2016-2020, in particular during the Covid-19 lockdown, being involved in the design of contingency plans for the Spanish Ministry of Universities). He is currently or was Associate Editor of 18 international journals, and was recognized as IEEE Transactions on Fuzzy Systems Outstanding AE in 2008 and IEEE Transactions on Evolutionary Computation $\mathrm{AE}$ in 2019. Since 2004, he has taken many different representative positions with the European Society for Fuzzy Logic and Technologies (EUSFLAT) and the IEEE CIS. 